\title{
POÉTICAS PARA UMA MICROPOLÍTICA INSTITUCIONAL
}

\begin{abstract}
Resumo: Os liames do poder sobre a vida e o corpo são questionados através de proposições poéticas que versam sobre as amarras institucionais, o produtivismo acadêmico e suas submissões. Sem fazer uma análise pormenorizada das formas históricas de dominação sobre corpos, da servidão, do valor do trabalho em salas de aula e do trabalho das mulheres, especialmente o de professoras e artistas infames, o artigo traz esses elementos a fim de tensionar o poder que perpassa os cruzamentos entre a arte e a educação. Numa perspectiva micropolítica, com Deleuze, Guattari e Foucault, este trabalho trata dos aparelhos de captura e procura mostrar as forças imanentes a um estudo e a um espaço que reverbere o que se cria. Pensa-se a constituição de um studium que possibilite a criação de um spatium qorpo pautado pela liberdade intelectual.
\end{abstract}

Palavras-chave: Submissão. Poder. Corpo. Aparelhos de Captura.

\section{APARELHAGEM}

Em uma conversa, o professor universitário Michel Foucault é questionado sobre a vida acadêmica, sobre a qual versa com a exclusão dos estudantes universitários da vida real (2010, p. 15-16). O problema do que o autor francês compreende como sistema de isolamento intelectual é que ele tira as forças do estudo e as dá para uma vida universitária de ritos iniciáticos (avaliações e bancas examinadoras) e teatralizações (colações de grau e outras pompas). Os estudantes, mesmo o proletariado que Foucault observou estar chegando à universidade francesa nos anos 1970, são reabsorvidos socialmente no mercado de trabalho, estando aptos a reproduzir o modelo burguês capitalista que sua vida universitária os faz assimilar, apesar de alguns momentos contestatórios, como o movimento estudantil de 1968, comentado pelo autor. Na medida em que garantem sujeitos aptos a manterem a sociedade funcionando em todos os seus aspectos, escolas e universidades são instituídas para a propagação de aparelhos de Estado. Este se ocupa com formações de "funções públicas" endógenas e exógenas ao próprio aparelho e a seu "sistema de servidão maquínica" (DELEUZE; GUATTARI, 1997, p. 116). A questão tratada por Foucault se formula perante a centralidade da formação (a importância da formatura) e a inoperância e/ou a inexistência da intensificação nos estudos.

Numa pesquisa desenvolvida junto à Pós-Graduação em Educação Brasileira, defendemos a existência de um studium e, para tanto, é necessário pensar porque hoje, mais do que nos tempos de Foucault, ele parece inviável dentro de todos os âmbitos da vida escolar e acadêmica. Espaço de leituras, elaborações e escritura, por studium concebemos o lócus existencial do que não está pronto, sendo possível observar projetos e construções em processo e as conexões e articulações entre variados sistemas de pensamento. Para Roland Barthes, o studium expressa uma aplicação de gostar tanto de

\footnotetext{
${ }^{1}$ Artista Visual, Doutora em Educação, UFRGS. E-mail: paola.zordan@gmail.com. POÉTICAS PARA UMA MICROPOLÍTICA INSTITUCIONAL
} 
algo a ponto de produzir um "investimento geral, ardoroso", fruto de interesse, ocupado em decodificar os elementos e estabelecer uma consciência sobre o assunto ao qual se dedica (1984, p. 45-46). O que um studium efetiva é o que Foucault traz como a elaborada artesania na fabricação de uma aula, de uma conferência, de uma fala cuja "honestidade bruta" (2010, p. 22) dá a ver um processo intelectual aberto a aprendizagens e interlocuções.

Ao comprometer-se com a luta pela qualificação do trabalho intelectual, a pesquisa, que se faz aqui, implica a obtenção de condições minimamente razoáveis para estudo a fim de que um studium exista. Isso nos obriga a operar junto a regulamentos implícitos, que incidem em condutas mais ligadas à realização produtiva do que ao estudo envolvido com leituras, anotações, desenhos e escrituras. Embora não se pretenda fazer uma análise do que afasta professores e alunos da prática do estudo, nem se tenha aqui a intenção de descobrir o modo como tais regulações são legitimadas no cotidiano das instituições educacionais, o problema dessa legitimação é tratado de maneira poética, junto a intervenções e manifestações em espaços públicos (parques e praças) e institucionais (escolas e universidades). O que está em jogo são discursos que sustentam, em linhas de pesquisa e nos segmentos administrativos que as estabelecem, o quanto um professor, ou mesmo um aluno, está ou não apto a publicar, orientar e receber fomento. Não se trata de buscar documentos de Estado para diagnosticar em suas leis, diretrizes e regulamentos ordens que perpetuam aprisionamentos de um pensar que se quer livre, mas de trazer, por formas de expressão envoltas na pesquisa acadêmica, o sentimento cotidiano de desigualdades e de compra e venda de favores, suaves corrupções legitimadas na instituição em suas formas práticas e operacionais. Não há um dado preciso para dizer quantos docentes sentem esse tipo de exclusão e o quanto, retomando as observações de Foucault, as pompas legadas às letras das avaliações que recaem sobre a produção acadêmica afastam intelectuais da vida universitária.

De fato, não ignoramos a opressão política que permeia o estabelecimento do produtivismo acadêmico (MACHADO; BIANCHETTI, 2001). Todavia, nos deteremos no conflito de linguagens que opera um "jogo de exclusão, recusa e esquecimento" (FOUCAULT, 2010, p. 20). O que se toma como "opressão" pode ser transposto às exigências de pertencimento a determinados números de textos em períodos de três, agora quatro anos, em segmentos de publicação dita "qualificada". Tal jogo acontece no âmbito do que denominamos spatium, que não configura exatamente espaço de informação, publicação, divulgação e exposição de movimentos de pesquisa e atividade intelectual. $\mathrm{O}$ spatium configura um espaço não burocratizado, ainda que dentro de instituições, de práticas, estudos e encontros que possibilitam a existência de aulas abertas, atividades corporais, musicais e artísticas, assim como outras situações de aprendizagem coletiva. Ao conceituar micropolítica em termos de uma "analítica das formações do desejo no campo social” (GUATTARI; ROLNIK, 2005, p. 127), Félix Guattari questiona os "equipamentos coletivos" que produzem um sistema de modelização dos comportamentos, programando, teleguiando e codificando "as condutas, os comportamentos, as atitudes, os sistemas de valor, etc." (GUATTARI; ROLNIK, 2005, p. 128). Investindo contra esse tipo de programa equipado por formas diversificadas de coerções, uma ação micropolítica artística possibilita a constituição de um spatium fora POÉTICAS PARA UMA MICROPOLÍTICA INSTITUCIONAL 
do cerceamento do sistema hoje vigente nas universidades, em especial o que opera na pós-graduação. As principais coerções são vividas pela emissão de "boletins de desempenho" que contabilizam apenas artigos em periódicos classificados nos três níveis superiores, não considerando, na pontuação docente, participação em eventos significativos na área de conhecimento, projetos de inserção social e outras interlocuções politicamente relevantes no que tange ao trabalho intelectual.

Como ato de resistência, uma micropolítica institucional favorece o trânsito de produções qualificadas por sua força poética, permitindo outra qualificação para a "produção intelectual qualificada", que é contabilizada somente por publicações em periódicos indexados e que pauta o atual mérito dos pesquisadores para estarem ou não aptos a proventos, fomentos e outras facilidades. O que aqui se apresenta - embora pertença, por aprovação do projeto, à área da Educação — faz borda com a Arte, ainda que sem reconhecimento dentro de seus sistemas e mercados específicos. Seja por confundir definições de científico, técnico e artístico; seja na dificuldade de enquadramento em nichos de conhecimento reconhecidos; seja pelo seu estranhamento dentro do próprio campo ou ainda por excesso de empiria; seja por seu desenvolvimento dentro de ateliês, oficinas, laboratórios; seja pelo tempo vivido pelo pesquisador dentro das escolas básicas, a proposta se afirma como poética e micropolítica, mesmo quando rejeitada, exatamente por sua proposital imprecisão, pelos agentes autorizados a legitimar suas produções.

Em Vigiar e Punir, aprendemos que o poder só pode ser analisado nos mecanismos pelos quais se faz exercer, sendo por eles que compreendemos o modo pelo qual a sociedade define o que é certo e o que é errado, legal e ilegal e "como ela exprime todas as infrações e todas as transgressões feitas à sua lei” (FOUCAULT, 2010, p. 32). A vigilância, os juízos e as punições são exercidos sobre os corpos: este, com suas "submissões ativas" aguardando pareceres favoráveis, encontra-se à mercê de julgamentos que o inserem ou o repelem, ejetando suas forças dos espaços políticos e das relações de poder. A obtenção de credenciais, as escolhas, as seleções, as distribuições de víveres e vagas envolvem aquele poder insignificante exercido no árbitro sobre "pequenas desordens de conduta" (FOUCAULT, 2010, p. 214). Contra esse corpo que se assujeita às regras, trazemos, com a inspiração de José Joaquim Campos Leão (1829-1883), poeta, dramaturgo e professor gaúcho do século XIX, o registro de outro tipo de corpo, que denominamos qorpo. Assume-se o projeto de Qorpo Santo, autor da Ensiqlopédia, tipógrafo longe das grandes cidades tropicais do Império e também das cidades em pleno desenvolvimento às margens do Plata. Qorpo Santo foi considerado um louco por perverter a gramática e criar estilo literário próprio. Viveu com falta de dinheiro, mal compreendido por seus conterrâneos, mostrando como os construtos epistemológicos academicistas, de forte influência no período em questão, impedem uma vida confortável aos homens que criam algo novo (MARQUES, 1993). Desde a segunda metade do século XIX, primeiro importando profissionais europeus e depois formando seus próprios bacharéis, o Brasil apresenta uma cultura pautada por valores acadêmicos, o que se faz sentir na economia, na sociedade e na obra de todos os que pervertem valores econômicos e sociais. 
Ao contrapormos um infame a valores eruditos estabelecidos, afirmamos um qorpo desejante, pleno em suas intensidades e riscos, que dificilmente se adestra. Poesias, performances, instalações visuais em locais públicos, o trabalho estritamente plástico, entre outras manifestações, tendem a criar um spatium qorpo que constitui certa turbulência nas instituições. Quando o produto advindo de um studium não pode ser computado e o spatium por onde ele flui é boqueado, torna-se estratégico estudar esse qorpo e as proposições poéticas nele implicadas. Destarte, independentemente do quanto uma proposta envolva ou não a densidade de muitos estudos, ela somente será considerada palatável dentro do sistema que legitima e valida a produção intelectual se o studium pertencer ao spatium aparelhado regimentalmente. Trata-se de investigar as maneiras pelas quais tais manifestações são ou não absorvidas, o quanto entram ou são ignoradas nos regimentos e como o poder as captura ou as exclui via resoluções que definem o que efetivamente se pode nas instituições.

Na célebre conversa entre Foucault e Deleuze, Os Intelectuais e o Poder, a analogia entre escolas e prisões se explicita (FOUCAULT, 2010, p. 41), a ponto de Deleuze fazer a relação da repressão policial com "a repressão no ensino" (FOUCAULT, 2010, p. 42). Foucault expressou sua vergonha das prisões (FOUCAULT, 2010, p. 152), e cabe a nós, pesquisadores da Educação, tratar da vergonha sentida perante tanto a precariedade das escolas quanto o sistema de avaliação da produção intelectual. Ao excluir o trabalho empírico das pesquisas voltadas ao espaço escolar, esse sistema afasta a prática de ensino básico do studium. Sendo o sistema penal facilmente e comumente comparável ao sistema de avaliações institucionais, trata-se de "captar o ponto de revolta e mostrá-lo" no que diz respeito à avaliação da produção intelectual (FOUCAULT, 2010, p. 35). A fiscalização, as inúmeras interdições e todas as coações que se fazem valer dentro das instituições atestam a total puerilidade do exercício do poder que chocou Deleuze e Foucault no início dos anos 1970 e que, todavia, ainda é percebida atualmente. O antigo suplício público passa, entretanto, a outras formas de castigo, e as súplicas cedem aos recursos contestatórios, que, embora raros, permitem resistência a pareceres, reprovações e juízos excludentes. Embora não seja possível uma compreensão de como regras estabelecidas institucionalmente funcionam como cooptação para determinadas práticas de avaliação, podemos seguir as linhas que levam à exclusão dos lugares de poder e à repetição de textos e discursos como modo de sobrevivência dentro do instituído. Sem a intenção de analisar o modo como, serenamente, uma professora na pós-graduação — dentro de uma política departamental em que essa carga horária não é computada na divisão de encargos e ainda com uma família para alimentar e todo o serviço doméstico para fazer — precisa escrever dois artigos para um rol muito estreito de veículos científicos ao ano, trazemos esse exemplo para poder dizer do insuportável que permeia esse tipo de vida. Para entender como se exerce tal sistemática de submissão, não é necessário buscar explicações na dominação exercida sobre os corpos femininos nem no controle da produção pelos agentes que avaliam escores de publicações. Interessa, sim, mostrar onde se dá a exclusão de uma produção pouco passível de uma análise nos moldes clássicos, aqui tratada no espectro mais amplo do studium, mas cujo estudo não se ordena. Qual é a relação dessas formas arbitrárias de controle com a "tirania bruta" de uma moral instituída, que estabelece o êxito "da ordem sobre a desordem” (FOUCAULT, 2010, p. 
41)? Para fazer aparecer, dar a ver como opera tal sistema - que, tal como o regime penal combatido por Foucault, "não é mais suportado pelas pessoas" (FOUCAULT, 2010, p. 34) - cabe "tomar a palavra, fazer cair a compartimentagem, formular o que é intolerável” (FOUCAULT, 2010, p. 29).

O que não se tolera se faz sentir nos corpos, sendo possível pontuarmos alguns sintomas dentro de percepções cotidianas em instituições educacionais. Por ser "feita de sintomas e avaliações mais do que medidas e propriedades" (DELEUZE; GUATTARI, 1997, p. 185), essa percepção trata da insustentabilidade de um modo de vida cada dia mais difícil de ser vivido, ou seja, uma vida acadêmica sem studium, uma produção intelectual sem spatium. O que se percebe é o sufoco de "existências reais" que possuem lugares e datas, no caso, professoras (ligadas às artes, mães e donas de casa cujos rendimentos não são suficientes para o pagamento de serviçais) e alguns professores sensíveis a esse sufocamento, que estão, tal como os homens infames de Foucault, tendo parte de suas existências "efetivamente riscadas e perdidas" por serem escandalosas, enraivecidas e desprezíveis nas redes que estabelecem os poderes institucionais (FOUCAULT, 2010, p. 206). Talvez se exprimam tal qual as vidas que Foucault trata como "lisas", sentidas no afinco e na derrota, "destinadas a passar por baixo de qualquer discurso e a desaparecer" (FOUCAULT, 2010, p. 207), não como pessoas, mas como artistas, criadores, inventores e intelectuais. Pressupondo-se que esse desaparecimento se deva à impossibilidade de fazer valer uma produção não exatamente enquadrada, seus estudos vêm sendo sufocados "como se sufoca um grito, um fogo ou um animal" (FOUCAULT, 2010, p. 205).

Contudo, é exatamente do ponto intenso em que uma vida se choca com o poder, se debate contra ele, tenta "escapar de suas armadilhas" (FOUCAULT, 2010, p. 208), que extraímos a poética aqui apresentada. Mesmo sufocado, o pensamento que faz valer sua liberdade não pode ser apagado. Não se trata de debater o aniquilamento da vida intelectual, sentido no estudo submisso às regras de execução, mas, sim, de tirar desse impasse forças para criar outras proposições. Um trabalho em processo, aberto a $n$ perspectivas, que explora camadas de discurso e segue a filologias de autores, apresenta devires intermináveis, e projetos e relatórios dentro dos formatos exigidos não são capazes de exprimi-los. Trata-se de uma poética que não pode ser circunscrita a uma “ordem", pois envolve desde minúcias dentro da própria produção acadêmica qualificada pela classificação dos periódicos em que ela é publicada a projetos performáticos e intervenções urbanas inclassificáveis. Apesar de sua quase insustentabilidade institucional, são nesses devires não capturáveis pela produção não indexada que se faz valer uma vida intelectual plena, em que saberes filosóficos, científicos e poéticos traçam um plano de consistência variado e heterogêneo. Em sua conversação com Deleuze, Foucault trata do saber intuitivo das massas, da capacidade de um grupelho ou uma coletividade falar das sujeições aos quais estão submetidos, destarte um "sistema de poder que barra, interdita, invalida esse discurso e esse saber" (FOUCAULT, 2010, p. 39).

PARA NÃO SEGUIR UM MÉTODO QUE APRISIONE

POÉTICAS PARA UMA MICROPOLÍTICA INSTITUCIONAL

ZORDAN, Paola. Poéticas para uma micropolítica institucional. Crítica Cultural - Critic, Palhoça, SC, v. 11, n. 2, p. 273-285, jul./dez. 2016. 
A experiência de formar docentes em cursos de graduação no ensino superior e agentes educativos em instituições culturais (educação não formal) leva ao questionamento das subjetivações inerentes ao estabelecimento das relações de poder, em especial as que submetem o corpo a amortecimentos e impedem a existência de um qorpo. Perante inquietações vividas em observações de salas de aula na escola básica e na universidade, podemos problematizar: os saberes expressos não apenas por textos, mas também por outras formas de expressão; o valor de uma aula dentro das amarras das avaliações acadêmicas; e o que vale uma vida dedicada a uma instituição. Ao contabilizarem-se apenas artigos indexados em periódicos avaliados dentro de um sistema hierárquico, o desempenho acadêmico em sala de aula, sem o qual não é possível o studium, está em desvalia. Ao dedicar-se às relações de ensino e aprendizagem com os alunos em experiências não apenas textuais e ao preparar atividades de sala de aula de acordo com as características e os referenciais de cada grupo, um professor não consegue obter as qualificações exigidas. As exigências ocorrem dentro do sistema de pósgraduação em que se contabiliza apenas a produção indexada em periódicos classificados sobre somente os três extratos superiores dentro de uma área específica, sem considerar os aspectos interdisciplinares de várias pesquisas, especialmente os da Educação. $\mathrm{O}$ intuito é criar formas de resistência às macroestruturas institucionais, desenvolvendo, junto à universidade pública, projetos poéticos para pensar a valorização do trabalho intelectual e artístico, tendo a política estética de Nietzsche e a ética de Spinoza como base.

O que vivemos na área da Educação na segunda década do século XXI leva a operar com Michael Foucault, sendo a análise dos dispositivos em questão situados desde o final do século XVIII o que nos permite compreender a formação das instituições modernas, a emergência do biopoder nos governos e a idealização da disciplina e da produtividade em escolas e universidades. Os estudos esquizoanalíticos e foucaultianos sugerem procedimentos que, uma vez tomados como métodos, deixariam de lado a novidade do qorpo e do pensamento desejada. Embora seja possível traçar um plano de investigação para análises num traçado de linhas ao modo de Deleuze, os conceitos aqui tratados são consubstanciais às poéticas citadas, considerando que os estudiosos "deveriam se sentir livres para inventar métodos capazes de resolver os problemas das pesquisas que estão fazendo" (BECKER, 1997, p. 13). Ao criarmos novos procedimentos para lidar com problemas que ainda estão por vir, no caso, poéticas desenvolvidas como produção intelectual, corremos riscos. Tal maneira de tratar o material desenvolvido na pesquisa, especialmente os produzidos nas inúmeras proposições poéticas, retomam o que outros projetos já desenvolveram, mas não sem o enfrentamento de resistências, como o pesquiZação. O "z" desloca o hífen das antigas pesquisas-ações "de finalidade prática" (THIOLLENT, 1985, p. 26), afirmando os ziguezagues das linhas de Deleuze, mas sem perder o intuito de produzir intervenções concretas, no caso, proposições poéticas elaboradas junto ao estudo dos conceitos implicados na constituição do arquivo. O " $z$ " se diferencia das "pesquisas-ação", ainda que a homofonia preserve o conceito de estudo dinâmico sobre problemas situados numa práxis social que apresenta "variáveis imprecisas dentro de um contexto em permanente movimento", funcionando, 
efetivamente, como diz Michel Thiollent, num vaivém que, dependendo de quem lê, pode ser entendido como "falta de rigor" (THIOLLENT, 1985, p. 33).

Ação microrrevolucionária que põe em questão "a totalidade do poder e sua hierarquia" (FOUCAULT, 2010, p. 40), uma pesquisa em torno de subjetivações infames de mulheres em sala de aula, professoras e artistas fora do sistema da arte, com foco no corpo e suas políticas, faz uma espécie de inquirição, ao estilo de Foucault, deixando falar o menor, o irrelevante, "o detalhe sem importância obscuridade, os dias de glória, a vida comum, podem e devem ser ditas, ou melhor, escritas" (FOUCAULT, 2010, p. 216). Assim, a escrita de aforismos, fragmentos e notas dispersas ganha força na elaboração das propostas poéticas. O que se quer com esse traçado aberto é movimentar o que esses autores chamam uma "máquina de guerra" a fim de implodir a separação entre forças de trabalho intelectuais e corpóreas em sua clausura e escape, em especial no que tange à subjetividade feminina. Assujeitadas tanto pelas submissões operadas na produção intelectual quanto pelas demandas domésticas e pelas dificuldades de obter auxílio efetivo nos cuidados com idosos e crianças, assim como as de custear despesas nesse âmbito, docentes mulheres comumente se dizem "com a corda no pescoço". A problematização desse assujeitamento se estrutura junto às poéticas propostas, que acontecem em espaços públicos e dentro das instituições educacionais, sendo o corpo das próprias pesquisadoras professoras e as criações dos pesquisadores, envolvendo instalações, performances, criações de figurino e coreografias, o material a constituir os documentos que podem tanto ser mote para a criação como materiais a serem investigados por outras pesquisas.

\section{Dispositivo plástico de pesquisa em saguão de Faculdade (foto do autor).}



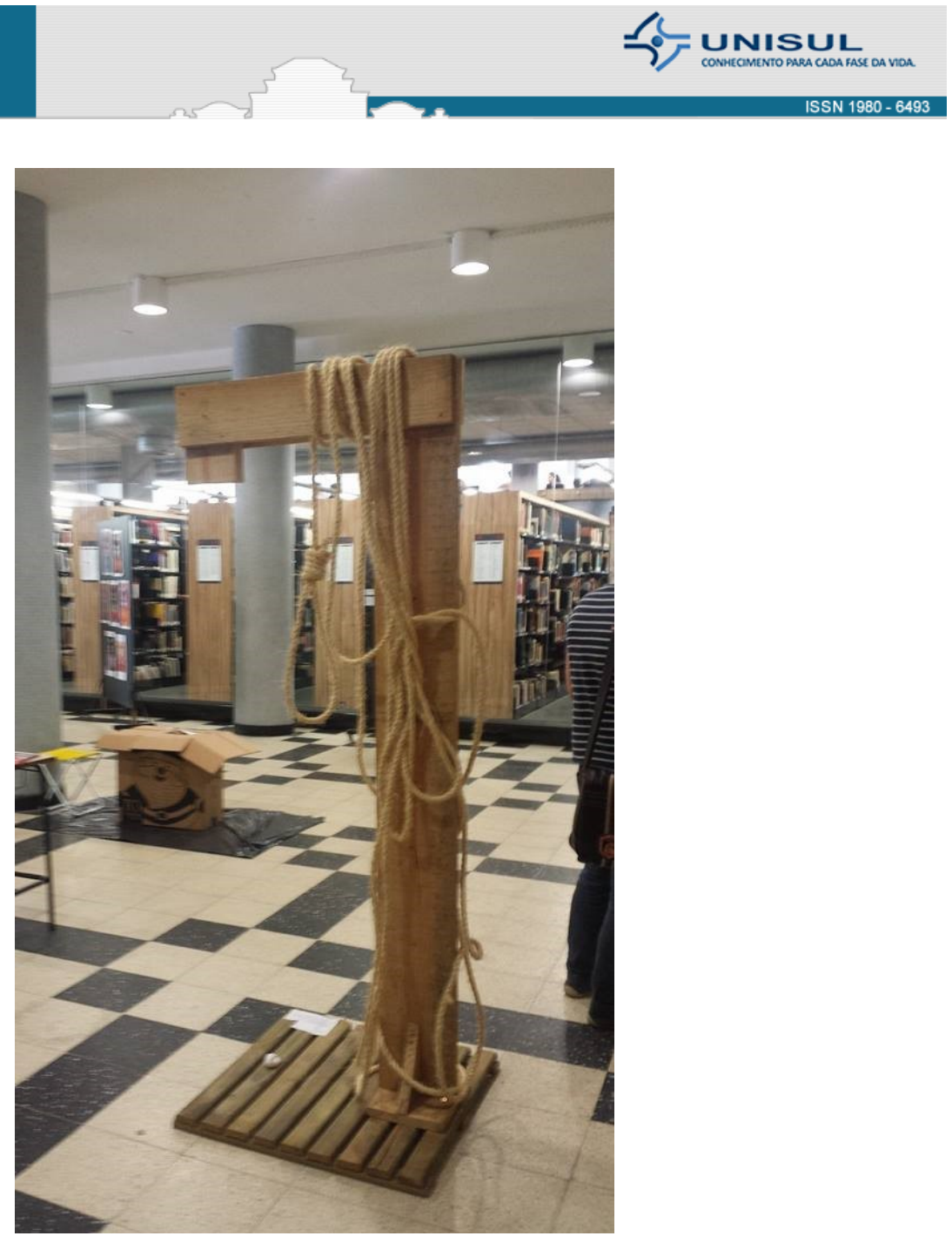

PEQUENO COMBATE

Os grupúsculos constituem "aparelhos de combate”, diz Deleuze a Foucault (2010, p. 39), isto é, aparelhos dentro da aparelhagem maior, máquinas que resistem ao que os autores, juntamente com Guattari, combateram. Não são grandes centrais de poder, mas uma dominação estável, uniformizadora, "morna" de um aparelho disciplinar inerente à nossa sobrevivência institucional. Na impossibilidade de existirem "relações de poder que sejam completamente triunfantes e cuja dominação seja incontornável" (FOUCAULT, 2010, p. 232), o problema não se analisa pela hierarquia social, tampouco pela distinção de classes econômicas, mas, sim, pela singularidade dos jogos de interesse. Deleuze compreende que há "investimentos de desejo que modelam o poder e o difundem", de modo que as relações de poder passam por muitas outras coisas além das contagens, classificações e graduações dos aparelhos de Estado. Embora estes estejam permeados por protocolos que definem o que se pode e quem pode, são nos pequenos enfrentamentos cotidianos e não nas centrais de governo em que o poder captura melhor as forças que eles engendram suas práticas. O poder opera totalizações, mas, quanto mais particular e subjetiva for essa totalidade - seja de uma significação imperativa, seja a coação de um corpo sobre o outro - mais o poder se faz valer em cada um de nós. Ao invés do totalitarismo de um poder centralizador, vivem-se inflações subjetivas de poder não aberrantes, táticas locais e individuais para encerrar embates de forças incessantes, cujas 
técnicas de controle impedem o excesso do próprio poder que se estabelece. Trata-se de uma perspectiva de análise que compreende o conjunto dos atuais aparelhos de Estado, em especial nos dispositivos educacionais, uma multiplicidade de aparelhos de captura. Um aparelho de captura consiste numa "zona de recorrência" que "opera por estratificação" (DELEUZE; GUATTARI, 1997), de princípios codificados. Tais princípios são régios e constituem regimes de signos produtores e verdades, discursos que ressoam no estabelecimento de crenças. Numa homogeneização totalizadora de tudo o que resta fora dos códigos instituídos, o aparelho se faz valer de algumas formas, as quais ele isola "para controlar ainda mais estritamente as relações com esse resto" (DELEUZE; GUATTARI, 1997, p. 123). A forma das aparelhagens se diversifica de acordo com o contexto, e, seja no âmbito do aparelhamento (quando se dá a absorção do produto), seja no âmbito da resistência (quando esse produto é ejetado, desconsiderado, eliminado, deletado), a forma se define por processos maquínicos, e não por modos de produção (DELEUZE; GUATTARI, 1997, p. 126).

Contra a resignação de que a instituição "é assim mesmo", contra a acomodação que impede um modo menos sufocante de trabalho institucional, há que se construir "fluxo por fluxo e segmento por segmento as linhas de experimentação" (DELEUZE; GUATTARI, 1996, p. 24). São linhas implicadas na máquina de guerra nômade, atravessando o espaço liso que nas instituições ainda se faz valer num qorpo. Ao invés de combater o dragão do Estado, trava uma luta microscópica contra forças invisíveis e silenciosas que o derrubam. Ao erguer esse qorpo, aplicado num studium que cria seu próprio spatium, buscamos uma produção fora das amarras institucionais e livre de avaliações reguladoras. Essa produção advém de "mecanismos coletivos que, ao mesmo tempo, conjuram e antecipam a formação de um poder central" (DELEUZE; GUATTARI, 1997, p. 121), sendo a produção artística a mais propícia para tangenciar essas antecipações e para conjurar o que vem sendo um entrave para seu próprio desenvolvimento. Aqui nos deteremos numa proposta já realizada, cuja poética problematiza diretamente os liames do poder na figura dos enforcados e abandonados da sorte.

Com a falsa e questionável infâmia dos grandes malditos, tal qual o Marquês de Sade (FOUCAULT, 2010, p. 210), buscamos o devir-imperceptível, intenso, de um qorpo que perpassa os modos de produção aos quais estamos atados. Mesmo dentro de uma análise, trata-se de "fazer existir, não julgar" (DELEUZE, 1997, p. 153), afirmando a existência segredada pelos nômades, que movimentam uma máquina de guerra por espaços não institucionalizados, sem legislação, sem pactos contratuais. Seguindo forças animais, vegetais, hídricas, minerais, essas "máquinas de pensar, de amar, de morrer, de criar" dispõem de forças vivas para fazer fulgurar o que está relegado às sombras (DELEUZE; GUATTARI, 1997. p. 18). Abandonada por Teseu, o homem de Estado,

Ariadne se enforca (DELEUZE, 1996, p. 50-53), somente assim desposando Dioniso, qorpo potencial de mortes e renascimentos propício para a arte (FOUCAULT, 1994).

MALHA em novembro de 2014 (foto de Tessália de Moraes).

POÉTICAS PARA UMA MICROPOLÍTICA INSTITUCIONAL 


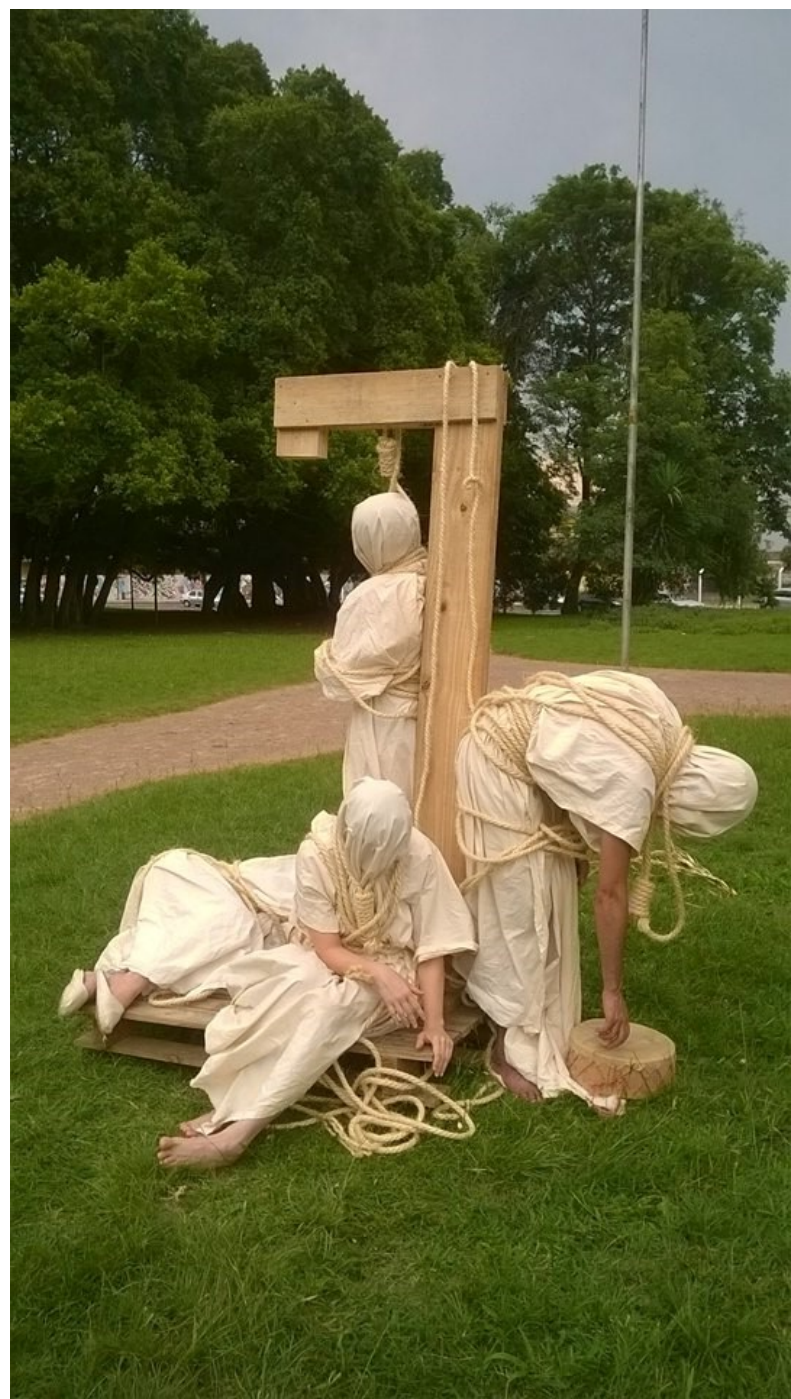

A CORDA NA FORCA

Para desenvolver um studium, criar um spatium, experimentar um qorpo, proposições artísticas, pedagogias performáticas e intervenções institucionais se criam junto ao pesquisar. Na dificuldade de situar um trabalho investigativo no campo híbrido entre a arte, a educação e a política, surgem diversas proposições para dar a ver a problemática das relações entre o ensino, os signos que permeiam as disciplinas do conhecimento e sua localização no modelo disciplinar da civilização. Aqui, mostramos uma dessas propostas, nomeada $A$ Corda na Forca, ação poética que questiona a servidão e a escravidão voluntária a fim de pensar o que vem a ser a liberdade. Consistiu numa escultura-manifesto-performance que agregou, numa praça, alguns participantes da pesquisa em performance e que teve razoável duração (quatro horas, sendo o planejado pela coordenadora oito horas), tendo ocorrido em espaço público durante a Semana da Consciência Negra. A praça se localiza no Centro Histórico de uma capital brasileira (dados precisos serão situados após avaliação), sendo o local, no século XIX, onde ocorriam os enforcamentos, conforme a então Constituição Federal em vigência, dos escravos condenados à morte (VOGT; RADÜNZ, 2012, p. 211). O trabalho envolveu 
elaboração de figurino, construção escultórica de um objeto de madeira que simulava uma forca, utilização do que poderia ser tratado tanto como um ready-made, à maneira de Marcel Duchamp, quanto como um objeto relacional, ao modo de Lygia Clarck — ou seja, uma corda de sisal de $1 \mathrm{~cm}$ de espessura e $220 \mathrm{~m}$ de comprimento - e figurinos de algodão cru que impediam a identificação dos corpos dos cinco performers envolvidos.

A poética $A$ 'corda foi desenvolvida em diálogo com a artista Dione Veiga Viera, que pensou esse cacófato para a intervenção, não realizada, no vão dos dez andares de escada de uma Faculdade de Educação de Universidade Pública (dados precisos serão situados após avaliação). A corda de sisal também foi utilizada como objeto relacional em manifestação em parque da cidade ocorrida junto a um grande monumento em homenagem à pátria (dados precisos serão inseridos após avaliação). Nessa manifestação, os artistas não institucionalizados Daniel Escobar e Carina Levitan colocaram a corda no pescoço e amarraram ao pedestal da estátua professores, designers e artistas ligados às universidades e à escola básica, os quais aderiram à convocatória que interpelava os participantes com as seguintes perguntas: Você se sente amarrado a uma instituição? Preso em tarefas infindáveis? Tais frases, divulgadas no cartaz da ação em redes sociais, foram inspiradas na observação feita por Guattari em uma de suas visitas ao Brasil, em 1982, quando comenta que Deleuze estava preso, plantado, "amarrado como uma cabra à universidade" (GUATTARI; ROLNIK, 2005, p. 302). 
MALHA em novembro de 2014 (foto de José Silvio Camargo Amaral/ Zeh Poeta).

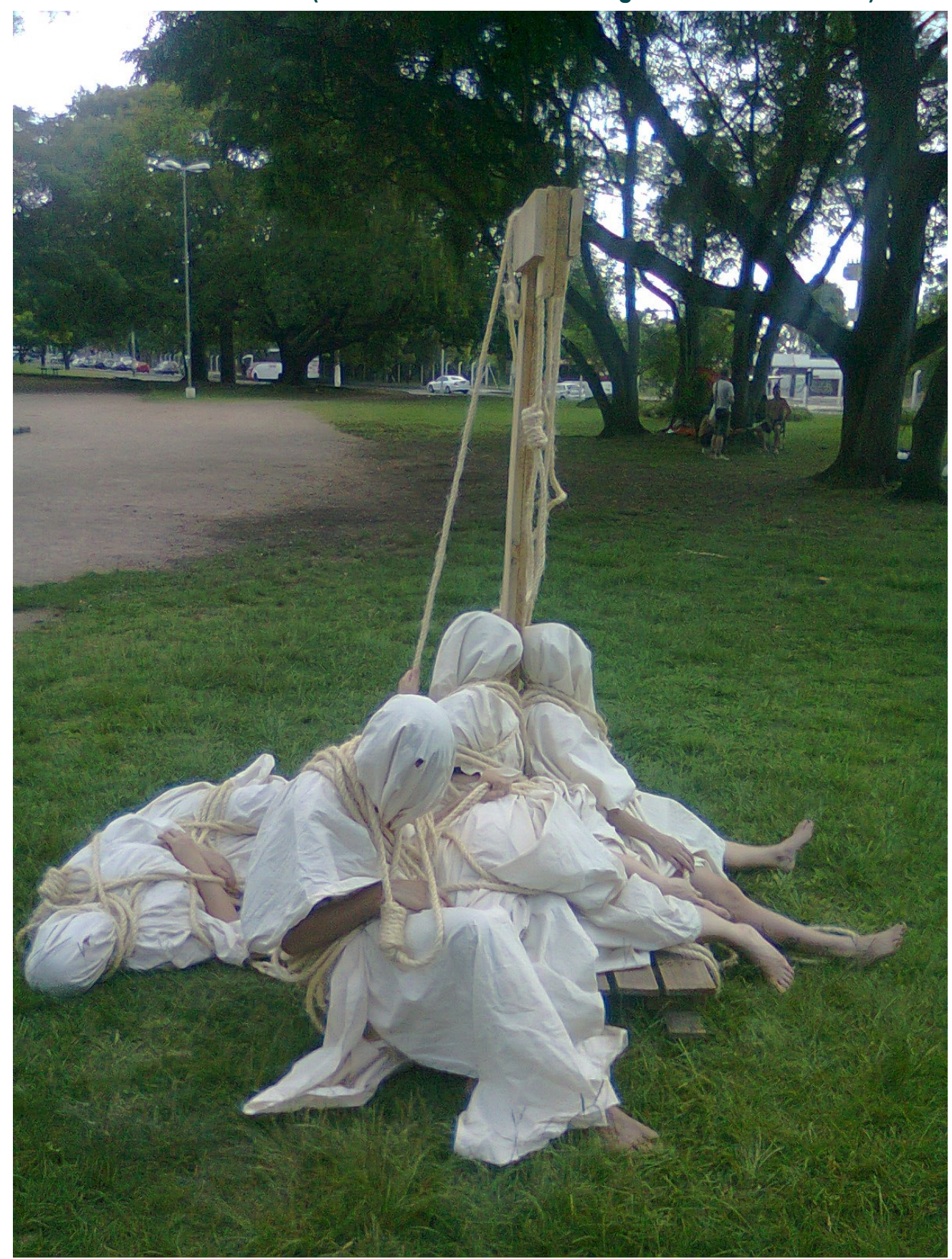

Há, por parte do público acadêmico a quem as ações foram divulgadas e às quais deliberadamente assiste, observações sobre comentários dos transeuntes e espectadores ocasionais. Contudo, não há a intenção de recolher impressões nem de contabilizar as fotografias, de conhecidos ou de quem foi surpreendido pela ação, publicadas e "curtidas" nas redes sociais, mesmo estimando o número de pessoas que tiverem contato com a escultura performática. Não se trata de uma pesquisa de recepção, e, sim, de criações advindas de estudos pós-estruturalistas com a finalidade de mostrar problemas e conceitos imanentes à vida de todos os pesquisadores. Embora não seja possível medir os impactos desse tipo de ação na comunidade e nos frequentadores regulares do local, basta saber POÉTICAS PARA UMA MICROPOLÍTICA INSTITUCIONAL 
que inúmeras questões são formuladas, que muitas pessoas param para contemplar a intervenção que, nem que seja por apenas uma tarde, institui, junto à pesquisa acadêmica, uma prática de liberdade.

PARA UM QORPO EXISTIR

Onde "o homem não representa mais nem mesmo um capital variável de sujeição, mas um puro elemento de servidão maquínica" (DELEUZE; GUATTARI, 1997, p. 168), resistimos fazendo uma pesquisa polimorfa que afirma "modos de produção não capitalistas" (DELEUZE; GUATTARI, 1997, p. 167). Ao tratar da enfermidade nata do homem de Estado, trata, conforme a literatura esquizoanalítica utilizada, de um Estado mutilador em que a liberdade intelectual, constantemente, mesmo que de modo tênue, é ameaçada. Essa liberdade se expressa no tempo dedicado ao studium e nos encontros que possibilitam a troca de experiências e outros saberes, os quais requerem spatium, sendo studium e spatium os elementos que possibilitam a consistência de um qorpo além do corpo assujeitado a órgãos e organismos. Sendo o serviço prestado ao poder público o "pressuposto do aparelho de Estado e da organização do trabalho" (DELEUZE; GUATTARI, 1997, p. 113), mesmo o serviço doméstico, sem garantias trabalhistas previdenciárias, atrela o corpo e a vida da pessoa aos seus deveres para com esse Estado via uma instituição (familiar, pública, privada). Todo e qualquer servidor está sujeito a uma "desgraça singular" (FOUCAULT, 2010, p. 208), que pode ser mostrada na opressão exercida sobre mulheres, nas dificuldades logísticas vividas pelas professoras e no esquecimento de intelectuais que primam pelos estudos e que, por razões a serem averiguadas, são excluídos dos fóruns entre pares e/ou não recebem financiamento. Numa ação poética que expõe, sem diretamente nada dizer, forças econômicas, políticas e morais implicadas no sufocamento institucional, trabalhando com o que há de intolerável na vida em sala de aula, na falta de estudo, no assujeitamento dos corpos e na subjetividade das mulheres, faz-se estratégico um trabalho artístico que exponha essas questões.

\footnotetext{
Não haverá libertação da fadiga enquanto o homem não estabelecer as suas próprias metas, no pleno exercício de suas decisões, aparelhando-se dos recursos necessários para atingi-los. Dar-lhe condições para agir em liberdade é trabalho dos que pensam (SCHÜLLER, 2001, p. 142).
}

Com os fragmentos de Heráclito, Donaldo Schüller nos ensina que "só o reconhecimento da indigência preserva a vida do indivíduo, da comunidade e da história no desencadear de atos verdadeiramente inaugurais" (2001, p. 163). Mostrar a infâmia é o que motiva as poéticas que, dentro de uma pesquisa acadêmica no campo da Educação, se propõem. Elas têm a intenção de combater uma "forma particular de poder, de coação, de controle" (FOUCAULT, 2010, p. 46), não implodindo com regramentos ou delatando abusos e mesmo as pequenas opressões que a instituição exerce. O que é preciso é expor os paradoxos que um qorpo, seja em sua matéria de expressão intensa, seja na materialidade que o compõe, discorre.

POÉTICAS PARA UMA MICROPOLÍTICA INSTITUCIONAL 
BARTHES, Roland. A Câmara Clara. Tradução: Júlio Casteñon Guimarães. Rio de Janeiro: Nova Fronteira, 1984.

BECKER, Howard. Método de Pesquisa em Ciências Sociais. São Paulo: Hucitec, 1997.

DELEUZE, Gilles. Crítica e Clínica. São Paulo: Editora 34, 1997.

O Mistério de Ariana. Tradução: Edmundo Cordeiro. Lisboa: Vega, 1996.

; GUATTARI, Félix. Mil Platôs: capitalismo e esquizofrenia. v. 3. Tradução: Aurélio Guerra Neto, Ana Lúcia de Oliveira, Lúcia Claudia Leão e Suely Rolnik. São Paulo: Editora 34, 1996.

Mil Platôs: capitalismo e esquizofrenia. v. 5. São Paulo: Editora 34, 1997.

FOUCAULT, Michel. Ariadna se ha Colgado. Archipiélago: cuadernos de crítica de la cultura, Madrid, n. 17, p. 83-87, jun. 1994.

Escritos).

Estratégia, Poder-Saber. v. 4. Rio de Janeiro: Forense Universitária, 2010. (Coleção Ditos e

GUATTARI, Félix; ROLNIK, Suely. Micropolítica: cartografias do desejo. 7. ed. Petrópolis: Vozes, 2005.

MACHADO, Ana Maria Netto; BIANCHETTI, Lucidio. (Des)fetichização do Produtivismo Acadêmico: desafios para o trabalhador-pesquisador. RAE: revista de administração de empresas, São Paulo, v. 51, n. 3, p. 244-254, maio/jun. 2011.

MARQUES, Maria Valquíria Alves. Escritos sobre um Qorpo. São Paulo: Annablumme, 1993.

SCHÜLER, Donald. Heráclito e seu (Dis)curso. Porto Alegre: L\&PM, 2001.

SPINOZA, Benedicto. Ética. Tradução: Tomaz Tadeu da Silva. Belo Horizonte: Autêntica, 2007. Edição bilíngue.

THIOllent, Michel. Metodologia da Pesquisa-Ação. São Paulo: Cortez, 1985.

VOGT, Olgário; RADÜNZ, Roberto. Condenados à Força: a escravidão e os processos judiciais no Brasil. Métis: história e cultura, v. 11, n. 21, p. 210-228, 2012.

Recebido em 16/09/2015. Aprovado em 22/06/2016.

Title: Poetics for an institutional micropolitcs

Abstract: The power moorings above life and body are questioned through poetics propositions. These discuss the institutional bonds, the academic productivity and its submissions. Without doing a detailed analysis of historical forms of domination upon body, the serfdom, the value of work in classrooms and women's work, specially female like teachers and infamous artists, introduce these elements in order to tension power in intersections between art and education. Inside micro policy perspective with Deleuze and Guattari's schizoanalysis and Foucault treat about capture apparatus. Intend to show a study and a space in immanent forces reverberate what creates it thinking the establishment of studium and enable the creation of spatium qorpo marked by intellectual freedom.

Keywords: War machine. Power. Body. Capture apparatus.

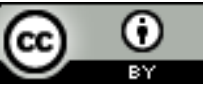

Este texto está licenciado com uma Licença Creative Commons Atribuição 4.0 Internacional

POÉTICAS PARA UMA MICROPOLÍTICA INSTITUCIONAL

ZORDAN, Paola. Poéticas para uma micropolítica institucional. Crítica Cultural - Critic, Palhoça, SC, v. 11, n. 2 , p. 273-285, jul./dez. 2016. 